Discussion Paper No. 756

\title{
ON THE THEORY OF EXHAUSTIBLE RESOURCES: \\ RICARDO vS. HOTELLING
}

\author{
Heinz D. Kurz \\ Neri Salvadori
}

September 2009

The Institute of Social and Economic Research

Osaka University

6-1 Mihogaoka, Ibaraki, Osaka 567-0047, Japan 


\section{On the Theory of Exhaustible Resources: Ricardo vs. Hotelling*}

By

Heinz D. Kurz and Neri Salvadori ${ }^{1}$

\section{Introduction}

Modern contributions to the economics of exhaustible natural resources, such as oil or coal, generally start from one form or another of the famous 'Hotelling Rule', first put forward by Harold Hotelling (1931). The Hotelling rule is an application of the concept of a competitive (uniform) rate profits to all processes in the economy, whether these are conservation or production processes. In the classical economists this rule is not yet to be found. Does this mean that their analyses are of necessity defective, incomplete or inferior? Or does it only mean that their argument relates to a world characterised by conditions that are different from those contemplated by the Hotelling Rule? Or is the rule implicit in their analyses and what is missing is only an explicit reference to royalties as something different from profits?

The paper answers these questions. As regards the classical economists we will focus attention on David Ricardo, the most 'classical' of all classical authors, and deal with Adam Smith only in passing. Takashi Negishi in the introduction to a collection of

Paper given at a seminar on 11 September 2009 at ISER (Institute of Social and Economic Research) of Osaka University by Heinz D. Kurz. The paper is a slightly revised version of Kurz and Salvadori (2009); all additions and changes are my responsibility. I should like to thank the participants at the seminar and especially Yoshiyaso Ono for most valuable discussions and useful comments.

$1 \quad$ Neri Salvadori thanks Francesco Chioni for the discussions they had while Chioni worked on his Laurea Thesis under Salvadori's supervision. 
essays devoted to the history of economic thought stressed that 'it is necessary to study theories that are regarded as past ones from the point of view of other research programmes.' (Negishi, 1994, p. xi) Alternatively, one might study theories that are regarded as incorporating the most recent vintages of economic knowledge from the point of view of earlier approaches to the problem at hand. Comparing old and new can be expected to shed new light on both and improve our understanding on what is truly novel, what is only an old result in a new garb and on what has been lost sight of in the course of time. As Negishi put it succinctly in another contribution: 'The history of our science should be used as a mirror in which the current theory reflects the knowledge of how it failed to succeed in the past. To learn from past theories does not impede the progress of our science. Progress often means, however, sacrificing something old. To make sure that we are going in the right direction, it is always necessary to see whether we have sacrificed something in error.' (Negishi, 1992, p. 228)

The Hotelling Rule, as it is typically presented, concerns the fact that the prices of resouces in situ need to increase over time at a rate that is equal to the competitive rate of profits. This fact seems in turn to imply another fact, namely, that all prices need to change over time. As mentioned in the above, the first fact follows from the requirement that the conservation of a resource is an economic activity which ought to yield to the proprietors of deposits of the resource the same rate of profits as it is obtained from any productive activity. The second fact is not immediately obvious.

The contribution of this paper may thus be summarized in the following way. While it is commonly thought that Ricardo's treatment of exhaustible resources is to be found first and foremost in the barely three pages of Chapter III of the Principles, 'On the Rent of Mines', this is actually not so. This chapter is in fact confined to a discussion of the rents of differently fertile mines in complete analogy to the rents of differently fertile lands. These rents arise because the exploitation of mines is typically subject to capacity constraints which imply that mines with different costs of extraction have to be operated at the same time. Ricardo develops an analysis of exhaustible resources rather in the context of a discussion of the difference between rent and profits. He begins this discussion in Chapter II, 'On Rent', in which he also criticizes Smith's cavalier and confusing use of the two concepts. Then, in Chapter XXIV, 'Doctrine of Adam Smith concerning the Rent of Land', he elaborates on his criticism of Smith's doctrine. He illustrates the fecundity of his own, Ricardo's, rigorous conceptualizations of these two 
important analytical categories in political economy and shows that Smith's analysis is bound to end in a muddle. As usual, Ricardo is 'desirous only to elucidate the principle' at work (Works, vol. I, p. 121), as he stresses in another context, and therefore bases his argument on strong assumptions. These assumptions, which we will explicate below, imply that the exhaustion of each and every deposit of an exhaustible resource will nevertheless leave the prices of all produced commodities unaffected over time. In this way Ricardo manages to isolate a particular phenomenon at hand and put it into sharp relief. In the context we are interested in, this refers to the distinction between differential rent and profits, where what Ricardo calls profits comprises what we nowadays call royalties. Hence royalties are there in Ricardo's analysis, but they are not easily identifiable as such.

The composition of the paper is the following. In Section 2 we specify two fundamental assumptions required in order to be able to establish the fact that all prices need to change over time because of the Hotelling Rule. We then confront these assumptions with alternative ones which, it will be argued, are characteristic of the analyses of Smith and Ricardo. Section 3 provides some evidence in support of this proposition in terms of passages taken from Ricardo's Principles. The main differences between the world in which all prices need to change over time because of the Hotelling Rule and the world about which Ricardo wrote are the following: (i) While Smith and Ricardo were aware of the exhaustibility of each and every deposit of a resource, they did not yet contemplate the case of the exhaustibility of the resource as a whole. (ii) Ricardo assumed that in order to meet the effectual demand for a resource, several deposits typically have to be worked simultaneously, because with regard to each deposit there is a capacity constraint that limits the time rate of raising the resource. Section 4 provides a mathematical formulation of the Ricardian point of view which allows one to compare the latter with the one underlying the Hotelling Rule. It concludes that Ricardo may have well come up with the modern interpretation of the Hotelling Rule had he considered the case of the exhaustion of a resource in its entirety as a realistic possibility, which apparently he did not. Hence, a modern formulation of Ricardo's view may complement the view expressed by the Hotelling Rule and thus render the overall 
argument about exhaustible resources more complete. Section 5 contains some concluding remarks. ${ }^{2}$

\section{Different assumptions - different worlds}

The modern interpretation of the Hotelling Rule presupposes that the following two assumptions hold:

(H1) The resource is available in homogeneous quality and in an overall quantity that is limited and that at any moment of time is known with certainty.

(H2) The amount of the resource that can be extracted in a given period of time, a year, for example, is only constrained by the amount of it left over from the preceding period.

(H stands, of course, for Hotelling.) In case one of these assumptions, or both, are not met, the Hotelling Rule has to be modified according to circumstances. It portrays a bold case of a resource whose exhaustion is actually foreseeable with certainty. The Rule

2 Aiko Ikeo has drawn our attention to the interesting paper by Kemp and Long (1984), who in the context of a discussion of the conventional $2 \times 2$ Heckscher-Ohlin trade model replaced the usual assumption of two non-depletable original factors of production ('Ricardo's indestructible powers of the soil') and allowed instead for one or two exhaustible resources ('Hotelling's destructible power of the soil'). They thus also combined ideas of Ricardo and Hotelling. However, their overall set-up differs markedly from the present one. In particular, they adopted a partial equilibrium framework by taking relative world market prices of final goods as given to the small open economy. In the case of exhaustible resources it is assumed that their exhaustion affects only production conditions in the economy under consideration, but not world market prices. They were also concerned only with homogeneous factors of production and thus not with extensive differential rent. The problem of whether Hotelling's fundamental idea is somewhere hidden in Ricardo's argument is not touched upon by them. 
does not rigidly fit (m)any cases in the real world. ${ }^{3}$ Yet it expresses an important principle at work that contributes to our understanding of what is going on in the latter. It can be objected that despite the fact that today we have a much clearer idea of what is still there of certain resources at a given moment of time and are possessed of much improved techniques to discover hitherto unknown deposits of resources, assumption (H1) is typically not met with regard to any single exhaustible resource. It is also not clear whether knowing precisely what is still there would mean much, because technical progress typically affects the economic importance of a resource. The discovery of new ways to use known substances as well as the discovery of the useful properties of hitherto unused substances may lead to substitution processes and in the extreme replace some given resource entirely by new ones. Also assumption (H2) is never strictly met. Typically, there are capacity constraints that limit the time rate of exploiting a deposit. These constraints are very often binding with regard to any single deposit of the resource, so that many deposits have to be exploited simultaneously in order to meet effectual demand.

We might go to the opposite extreme and postulate instead of assumptions (H1) and (H2) the following:

(R1) For each exhausted deposit of the resource another one with exactly the same characteristics is discovered and the cost of the search, in terms of labour and commodities, is always the same.

(R2) The working of each deposit is subject to a capacity constraint that limits the amount of the resource that can be extracted in a given period of time.

3 This is confirmed by Krautkraemer's survey article (Krautkraemer, 1998). He maintains, among other things: 'For the most part, the implications of this basic Hotelling model have not been consistent with empirical studies of nonrenewable resource prices and in situ values' (p. 2066). 'Other factors have overshadowed finite availability of the resource as determinants of the observed dynamic behavior of nonrenewable resource prices and in situ values' (p. 2087). And: 'It does seem to be a recurring tendency to overestimate the imminence of nonrenewable resource exhaustion' (p. 2103; emphasis added). Vis-à-vis the evidence provided by Krautkraemer the classical approach to exhaustible resources could be said to fare better. 
(R stands, of course, for Ricardo.) In case assumptions (R1) and (R2) replace assumptions (H1) and (H2) we are in a world that is much closer to that of the classical economists. Its properties are obviously different from those invoked in modern interpretations of the Hotelling Rule and therefore it should come as no surprise that Ricardo came up with a view which at first sight sits uncomfortably with modern interpretations of Hotelling's analysis. However, the reason is not that one of the analyses is right and the other wrong, but that they cover vastly different cases.

It goes without saying that there are intermediate cases beteen the two extreme ones: (H1) may be combined with (R2) or (H2) with (R1). Many additional cases could be studied which take into account, for example, that the discovery costs of new deposits are not constant or that the capacity constraint may depend on the amount of the resource that is still in situ.

We shall refrain from elaborating a richer typology of cases followed by a comparative investigation of them all. We focus attention rather on the case that was most probably at the back of Ricardo's mind. For this purpose we discuss, in the following section, what Ricardo wrote about exhaustible resources, the distinction between profits and rent and his criticism of Adam Smith's views on the matter.

\section{Ricardo on exhaustible resources}

In the Principles Ricardo defines rent rigorously in the following way:

Rent is that portion of the produce of the earth, which is paid to the landlord for the use of the original and indestructible powers of the soil. (Works, vol. I, p. 67; emphasis added )

He continues:

It is often, however, confounded with the interest and profit of capital, and, in popular language, the term is applied to whatever is annually paid by a farmer to his landlord. If, of two adjoining farms of the same extent, and of the same natural fertility, one had all the conveniences of farming buildings, and, besides, were properly drained and manured, and advantageously divided by hedges, fences and walls, while the other had none of these advantages, more remuneration would naturally be paid for the use of one, than for the use of the other; yet in both cases this remuneration would be called rent. But it is evident, that a portion only of the money annually to be paid for the 
improved farm, would be given for the original and indestructible powers of the soil; the other portion would be paid for the use of the capital which had been employed in ameliorating the quality of the land, and in erecting such buildings as were necessary to secure and preserve the produce. (Ibid.)

Adam Smith, Ricardo goes on to argue, did not stick to a rigorously defined concept when using the word rent. In Part II of Chapter XI of Book I of The Wealth of Nations, 'Of the Produce of Land which sometimes does, and sometimes does not, afford Rent', Smith gives an example of the timber business, timber clearly being a reproducible resource, in which he confounds the concepts of profits and rent (see WN I.xi.c.5):

He [Smith] tells us, that the demand for timber, and its consequent high price, in the more southern countries of Europe, caused a rent to be paid for forests in Norway, which could before afford no rent. Is it not, however, evident, that the person who paid what he thus calls rent, paid it in consideration of the valuable commodity which was then standing on the land, and that he actually repaid himself with a profit, by the sale of the timber? If, indeed, after the timber was removed, any compensation were paid to the landlord for the use of the land, for the purpose of growing timber or any other produce, with a view to future demand, such compensation might justly be called rent, because it would be paid for the productive powers of the land; but in the case stated by Adam Smith, the compensation was paid for the liberty of removing and selling the timber, and not for the liberty of growing it (p. 68; emphasis added).

Ricardo's criticism extends to Smith's dicussion of coal mines and stone quarries:

He [Smith] speaks also of the rent of coal mines, and of stone quarries, to which the same observation applies - that the compensation given for the mine or quarry, is paid for the value of the coal or stone which can be removed from them, and has no connection with the original and indestructible powers of the land. (Ibid.)

In Ricardo's view the distinction between profits and rent is crucial, because as capital accumulates and the population grows the two component parts of the social surplus are typically affected differently: 
This is a distinction of great importance, in an enquiry concerning rent and profits; for it is found, that the laws which regulate the progress of rent, are widely different from those which regulate the progress of profits, and seldom operate in the same direction. In all improved countries, that which is annually paid to the landlord, partaking of both characters, rent and profit, is sometimes kept stationary by the effects of opposing causes; at other times advances or recedes, as one or the other of these causes preponderates. In the future pages of this work, then, whenever I speak of the rent of land, I wish to be understood as speaking of that compensation, which is paid to the owner of land for the use of its original and indestructible powers. (Ibid., pp. 68-9; emphasis added)

Hence what Smith called 'rent' of coal mines or stone quarries is to Ricardo profits and not rent. But does Ricardo not contradict himself by giving Chapter 3 of the Principles the title 'On the Rent of Mines'? Scrutiny shows that this is not so. Chapter 3 is actually devoted to the rent of mines precisely in the sense Ricardo intended. The problem is the following: Why are mines possessed of different 'fertilities' operated simultaneously? Why is not the most 'fertile' mine exploited in full first, followed by the second fertile mine, and so on? The answer is straightforward: Several mines have to be worked at the same time because each one is typically subject to a capacity constraint that limits the amount of the coal or ore that can be extracted per unit of time. This constraint itself is seen to depend typically also on the amount already extracted. Effectual demand cannot be satisfied in the given circumstances by operating exclusively the most 'fertile' mine, because the required rate of output in order to meet effectual demand cannot be generated in this way. The amount of the resource 'which can be removed' (ibid., p. 68) will generally fall short of the resource in situ at the beginning of the extraction period. The same argument applies in the case in which there are several equally fertile minds. Yet, 'If there were abundance of equally fertile mines, which any one might appropriate, they could yield no rent; the value of their produce would depend on the quantity of labour necessary to extract the metal from the mine and bring it to market' (ibid., p. 85). This is generally not the case and differently fertile mines will have to be wrought simultaneously. The situation may change due to innovations, as Ricardo emphasizes with regard to coal: 'by new processes the quantity should be increased, the price would fall, and some mines would be abandoned' (ibid., p. 331). 
The absence of an abundance of equally fertile mines and the presence of a capacity constraint limiting the yearly output of any single mine in general necessitate the utilization of mines of different fertility in order to meet the effectual demand for the resource. In such circumstances, Ricardo stresses, it is the 'relative fertility of mines [which] determines the portion of their produce, which shall be paid for the rent of mines' (ibi., p. 330). Ricardo concludes that 'the whole principle of rent is here ... as applicable to land as it is to mines' (ibid., p. 330). When mines of different fertilities need to be wrought simultaneously, then this makes room for the emergence of (extensive) rents, exactly as in the case of the agricultural cultivation of land. This is rent in the true sense of the word and has nothing whatsoever to do with what nowadays we call 'royalties'. What we call 'royalties', Ricardo actually calls 'profits'.

Ricardo's use of the concept of profits for 'the compensation ... paid for the liberty of removing and selling the timber' is not surprising: timber can be sown and grown again, it is clearly not an exhaustible resource, but a reproducible good, and to the extent to which it is used as a produced means of production it is capital. But the use of the word profits for the compensation paid for the liberty of removing and selling coal or stones may be surprising: coal cannot be reproduced by men, neither can stones. However, new coal pits can always be expected to be discovered and the cost of the search is equal to the value of the mine, a value that decreases with the amount of the resource that has been removed. In other words, Ricardo did not need the word royalties since the minerals and ores etc. as such were not considered to be fully exhaustible in the foreseeable future. Both in Ricardo and in Smith we encounter time and again references to the finding of new deposits with no serious consideration given to the fact that such deposits, taken as a whole, are limited. This is the reason why Ricardo did not need a new concept in order to be able to deal with the case under consideration. The concept of profits was all that was required.

The fact that Ricardo did not elaborate what now is called the Hotelling Rule cannot therefore be considered an expression of a failure and a lack of analytical profundity on his part. It simply expresses a concern with a world in which the total exhaustion of certain resources was not yet considered a possibility worth studying.

What we now call royalties are a sub-category of profits. Profits are proportional to the value of capital invested or possessed, and in conditions of free competition the rate of profits 
obtained in oder to conserve the mineral in the ground has to be equal to the rate of profits obtained from any other production or conservation process.

If assumption (R1) held true, while each deposit would be exhaustible, the resource as such would not; and each deposit could in fact be treated as if it were a (reproducible) machine: the price of the new machine equals the cost of the search and the price of an old machine of age $t$ equals the value of the deposit after $t$ periods of utilization (see Kurz and Salvadori, 1995, pp. 359-60). The price of the resource in situ would change as predicted by the Hotelling Rule, but the price of the extracted mineral would be constant over time. ${ }^{4}$ In the next section we assume that (H1) and (R2) apply. We will show that also in this case the changes of the prices of the resources in situ may not need the introduction of intertemporal equilibria. But the model elaborated is more general and is of some interest in itself. It consists essentially of a modified version of a model we put forward in Kurz and Salvadori (2000). The novelty in the new formalization compared with the original one is to be seen first and foremost in the introduction of capacity constraints with respect to the exploitation of each single deposit of a resource.

\section{A formalization}

The formalization suggested here is based on the following simplifying assumptions. A finite number $n$ of different commodities, which are fully divisible, are produced in the economy and a finite number $m(>n)$ of constant returns to scale processes are known to produce them. Let $\mathbf{p}_{t}$ be the vector of prices of commodities available at time $t \in \mathbb{N}_{0}$ and let $\mathbf{x}_{t}$ be the vector of the intensities of operation of processes at time $t \in \mathbb{N}$. A process or method of production is defined by a quadruplet $(\mathbf{a}, \mathbf{b}, \mathbf{c}, l)$, where $\mathbf{a} \in \mathbb{R}^{n}$ is the commodity input vector, $\mathbf{b} \in \mathbb{R}^{n}$ is the output vector, $\mathbf{c} \in \mathbb{R}^{s}$ is the exhaustible resources input vector, and $l$ is the labour input, a scalar; of course $\mathbf{a} \geq \mathbf{0}, \mathbf{b} \geq \mathbf{0}, \mathbf{c} \geq, \quad \mathbf{0}, l \geq 0$. The production period is uniform across all

4 Adam Smith wrote about the discovery of new mines: 'In this search [for new mines] there seem to be no certain limits either to the possible success, or to the possible disappointment of human industry. In the course of a century or two, it is possible that new mines may be discovered more fertile than any that have ever yet been known; and it is just equally possible that the most fertile mine then known may be more barren than any that was wrought before the discovery of the mines of America' (WN I.xi.m.21). 
processes. It is important to remark that the inputs referred to in vector $\mathbf{c}$ are inputs of the resources as they are provided by nature; for example, extracted oil is not contained in c, but in $\mathbf{b}$, if $(\mathbf{a}, \mathbf{b}, \mathbf{c}, l)$ is an extraction process, or in $\mathbf{a}$, if $(\mathbf{a}, \mathbf{b}, \mathbf{c}, l)$ is a process that uses it, unless the extraction costs are nil. The $m$ existing processes are defined by quadruplets

$$
\left(\mathbf{a}_{j}, \mathbf{b}_{j}, \mathbf{c}_{j}, l_{j}\right) . j=1,2, \ldots, m
$$

Then define matrices $\mathbf{A}, \mathbf{B}, \mathbf{C}$ and (now) vector $\mathbf{I}$ as follows: ${ }^{5}$

$$
\mathbf{A}=\left[\begin{array}{c}
\mathbf{a}_{1}^{T} \\
\mathbf{a}_{2}^{T} \\
\cdot \\
\cdot \\
\cdot \\
\mathbf{a}_{m}^{T}
\end{array}\right], \mathbf{B}=\left[\begin{array}{c}
\mathbf{b}_{1}^{T} \\
\mathbf{b}_{2}^{T} \\
\cdot \\
\cdot \\
\cdot \\
\mathbf{b}_{m}^{T}
\end{array}\right], \mathbf{C}=\left[\begin{array}{c}
\mathbf{c}_{1}^{T} \\
\mathbf{c}_{2}^{T} \\
\cdot \\
\cdot \\
\cdot \\
\mathbf{c}_{m}^{T}
\end{array}\right], \mathbf{l}=\left[\begin{array}{c}
l_{1}^{T} \\
l_{2}^{T} \\
\cdot \\
\cdot \\
\cdot \\
l_{m}^{T}
\end{array}\right] .
$$

Assume that the annual consumption of commodities by profit (and royalty) recipients is proportional to a vector $\mathbf{d}$, which, for simplicity, is assumed to be given and constant over time, that is, independent of prices and quantities, including the quantities of the exhaustible resources left over at the end of each production period. In addition, the real wage rate, defined by a commodity vector $\mathbf{w}$, is taken to be given and constant over time. $\mathbf{y}$ is the vector of royalties earned with respect to the various natural resources; $\mathbf{q}$ is the vector of rents obtained in exploiting different deposits of them; $\mathbf{z}$ is the vector of the amounts of resources available. Technical innovations of any kind are set aside. All exhaustible resources are private property. In conditions of free competition there will be a (tendency towards a) uniform nominal rate of profits $r_{t}$ across all production activities in the economy. This implies that, for each time $t \in \mathbb{N}_{0}$, the following inequalities and equations are to be satisfied:

$$
\begin{aligned}
& \mathbf{B} \mathbf{p}_{t+1} \leqq\left(1+r_{t}\right)\left(\mathbf{A} \mathbf{p}_{t}+\mathbf{C} \mathbf{y}_{t}+\mathbf{C} \mathbf{q}_{t}\right)+\mathbf{l} \mathbf{w}^{T} \mathbf{p}_{t+1} \\
& \mathbf{x}_{t+1}^{T} \mathbf{B} \mathbf{p}_{t+1}=\mathbf{x}_{t+1}^{T}\left[\left(1+r_{t}\right)\left(\mathbf{A} \mathbf{p}_{t}+\mathbf{C} \mathbf{y}_{t}+\mathbf{C} \mathbf{q}_{t}\right)+\mathbf{l} \mathbf{w}^{T} \mathbf{p}_{t+1}\right] \\
& \mathbf{y}_{t+1} \leqq\left(1+r_{t}\right) \mathbf{y}_{t} \\
& \mathbf{z}_{t+1}^{T} \mathbf{y}_{t+1}=\left(1+r_{t}\right) \mathbf{z}_{t+1}^{T} \mathbf{y}_{t} \\
& \mathbf{x}_{t+1}^{T}\left(\mathbf{B}-\mathbf{l} \mathbf{w}^{T}\right) \geqq \mathbf{x}_{t+2}^{T} \mathbf{A}+\gamma \mathbf{d}^{T}
\end{aligned}
$$

5 Transposition of a vector or a matrix is denoted by superscript $T$. 


$$
\begin{aligned}
& \mathbf{x}_{t+1}^{T}\left(\mathbf{B}-\mathbf{l} \mathbf{w}^{T}\right) \mathbf{p}_{t+1}=\left(\mathbf{x}_{t+2}^{T} \mathbf{A}+\gamma \mathbf{d}^{T}\right) \mathbf{p}_{t+1} \\
& \mathbf{z}_{t}^{T} \geqq \mathbf{x}_{t+1}^{T} \mathbf{C}+\mathbf{z}_{t+1}^{T} \\
& \mathbf{z}_{t}^{T} \mathbf{y}_{t}=\left(\mathbf{x}_{t+1}^{T} \mathbf{C}+\mathbf{z}_{t+1}^{T}\right) \mathbf{y}_{t} \\
& \mathbf{z}_{t}^{T} \leqq \mathbf{z}_{t+1}^{T}+\mathbf{t}^{T} \\
& \mathbf{z}_{t}^{T} \mathbf{q}_{t}=\left(\mathbf{z}_{t+1}^{T}+\mathbf{t}^{T}\right) \mathbf{q}_{t} \\
& \gamma>0, \mathbf{p}_{t} \geqq \mathbf{0}, \mathbf{y}_{t} \geqq \mathbf{0}, \mathbf{q} \geqq \mathbf{0}, \mathbf{z}_{t} \geqq \mathbf{0}, \mathbf{x}_{t+1} \geqq \mathbf{0} .
\end{aligned}
$$

Inequality (1) means that nobody can get extra profits by producing commodities available at time $t+1$. Equation (2) implies, because of inequalities (1) and (11), that commodities available at time $t+1$ will only be produced if the ruling nominal rate of interest is obtained. Inequality (3) means that nobody can get extra profits by storing exhaustible resources from time $t$ to time $t+1$. Equation (4) implies, because of inequalities (3) and (11), that exhaustible resources will be stored from time $t$ to time $t+1$ only if the ruling nominal rate of interest will be obtained by this storage activity. Inequality (5) implies that the amounts of commodities produced are not smaller than the amounts of commodities required, and equation (6) implies that if an amount is larger, then the price of that commodity is zero. Inequality (7) implies that the amounts of exhaustible resources available at time $t$ are not smaller than the amounts of exhaustible resources available at time $t+1$ plus the amounts of exhaustible resources utilized to produce commodities available at time $t+1$, and equation (8) implies that if an amount is larger, then the price of that exhaustible resource is zero. Inequality (9) implies that at each time $t$ extraction of resource $j$ cannot be larger than $\mathbf{t}^{T} \mathbf{e}_{j}$, and equation (10) implies that if it is smaller, then the rent obtained by the owner of the deposit of resource $j$ is zero. The meaning of inequalities (11) is obvious.

The difference with a world in which there are no capacity constraints in the extraction of resources is close at hand: the elements of vector $\mathbf{t}$ are so high that inequality (9) is always satisfied as a strict inequality, then equation (10) implies that $\mathbf{q}_{t}=\mathbf{0}:$ in this case the model collapses to that analyzed in Kurz and Salvadori (2000).

The following observations are perhaps apposite. First, as the system gradually uses up its given stocks of exhaustible resources, moving from deposits that are less costly to operate to more costly ones, the overall (i.e. direct and indirect) amount needed of any such resource to 
produce one unit of the various commodities and indeed also to extract one additional unit of the resource itself may, and generally will, go up. Therefore, with a given net output vector the total amounts of the exhaustible resources extracted per period will increase over time: As the remaining stocks of the resources get smaller, the quantities used up get larger, at least for some time. Second, due to the decrease in the economic system's overall productivity, reflecting diminishing returns in the extraction industries, the rate of profits can be expected to fall over time. This mimicks Ricardo's result in his theory of ground rent. Third, there is no reason to presume that all resources will be fully exhausted. Since costs of extraction can be expected to rise, a point may come where it is no longer advisable to exploit deposits. (That this may very well be the case can be seen with reference to the extreme case in which more of a resource would be needed, directly and indirectly, than is being produced.) Fourth, without any technical progress or some deus ex machina, our economy would be doomed to extinction, at least in the long (or very long) run. This brings us to a discussion of the role of a 'backstop technology' in the economic system under consideration, whose role is precisely that of a deus ex machina or saviour of the world.

Despite the changes introduced in the above model, the procedure to prove the existence of a solution to the model of 2000 in the presence of a backstop technology can be applied also here. More precisely, let the processes $(\overline{\mathbf{A}}, \overline{\mathbf{B}}, \mathbf{0}, \overline{\mathbf{l}})$ be obtained from $(\mathbf{A}, \mathbf{B}, \mathbf{C}, \mathbf{l})$ by deleting all the processes using directly some natural resource (i.e., process $\left(\mathbf{e}_{i}^{T} \mathbf{A}, \mathbf{e}_{i}^{T} \mathbf{B}, \mathbf{e}_{i}^{T} \mathbf{C}, \mathbf{e}_{i}^{T} \mathbf{l}\right)$ is in the set of processes $(\overline{\mathbf{A}}, \overline{\mathbf{B}}, \mathbf{0}, \overline{\mathbf{l}})$ if and only if $\left.\mathbf{e}_{i}^{T} \mathbf{C}=\mathbf{0}\right)$ and let us assume that there is a scalar $r^{*}$ and there are vectors $\mathbf{x}^{*}$ and $\mathbf{p}^{*}$ which solve the system

$$
\begin{aligned}
& \mathbf{x}^{T}\left(\overline{\mathbf{B}}-\overline{\mathbf{A}}-\overline{\mathbf{l}} \mathbf{w}^{T}\right) \geqq \mathbf{d}^{T} \\
& \mathbf{x}^{T}\left(\overline{\mathbf{B}}-\overline{\mathbf{A}}-\overline{\mathbf{l}} \mathbf{w}^{T}\right) \mathbf{p}=\mathbf{d}^{T} \mathbf{p} \\
& \overline{\mathbf{B}} \mathbf{p} \leqq\left(1+r^{*}\right) \overline{\mathbf{A}} \mathbf{p}-\overline{\mathbf{l}} \mathbf{w}^{T} \mathbf{p} \\
& \mathbf{x}^{T} \overline{\mathbf{B}} \mathbf{p} \leqq \mathbf{x}^{T}\left[\left(1+r^{*}\right) \overline{\mathbf{A}} \mathbf{p}-\overline{\mathbf{l}} \mathbf{w}^{T} \mathbf{p}\right] \\
& \mathbf{x} \geq \mathbf{0}, \mathbf{p} \geq \mathbf{0}, \mathbf{d}^{T} \mathbf{p}=1 .
\end{aligned}
$$

Let us assume, further, that the processes corresponding to positive elements of vector $\mathbf{x}^{*}$, $(\hat{\mathbf{A}}, \hat{\mathbf{B}}, \mathbf{0}, \hat{\mathbf{l}})$, are exactly $n$ and that in the absence of exhaustible resources the economy would converge to these processes. Then the procedure used by Kurz and Salvadori (2000) is able to 
construct a solution also for system (1)-(11) despite the introduction of capacity contraints on the extraction of resources. Such a proof follows exactly the same lines and we will not provide it here.

What we want to stress here, on the contrary, is that the introduction of capacity constraints on the extraction of resources may introduce a further reason in support of the view that whereas the prices of resources in situ are bound to change at a rate equal to the rate of profits, all other prices will remain constant or will at any rate not follow the path of the former. We do not wish to assert that this fact will in fact happen, but that it may happen. This is so because the owners of deposits of resources get not only royalties, but also rents. The sum of royalties and rents for a given deposit may be constant even if royalties are changing, since rents are changing in equal amounts but in the opposite direction. To see this, consider an economy where capacity constraints are so high that production of consumption $\mathbf{d}$ requires the operation of the backstop technology and therefore processes $(\hat{\mathbf{A}}, \hat{\mathbf{B}}, \mathbf{0}, \hat{\mathbf{l}})$ are activated. As a consequence, vector $\mathbf{p}$ is determined and it may also be constant over time (it is so in the long run). This does not mean that production goes on in the same way year after year. Not at all: production changes potentially every year since the use of the resources reduces their availability. But the reduction of the availability of resources reduces also the rents and since the price of the extracted mineral is constant over time, the rent is reduced in exactly the same amount in which royalties are increased because of Hotelling's Rule.

\section{Concluding remarks}

The world to which applies the Hotelling Rule in its modern interpretation and the world to which applies the classical, especially Ricardian analysis are rather different. While the Hotelling Rule presupposes that a scarce natural resource is available in a known quantity and its extraction is not subject to any capacity constraints, Ricardo's treatment of exhaustible deposits does not contemplate the case of the exhaustion of the resource as a whole and allows for capacity constraints that limit extraction per unit of time with respect to each deposit actually known at a given moment of time. Both types of analyses are valuable and improve our understanding of the properties of economic systems that make use of wasting assets. It is then argued in terms of a model with exhaustible resources that incorporates what 
we think are the premisses from which Ricardo begins his reasoning, that the Hotelling Rule can be considered to be implied by it: the Rule concerns the resources in situ and requests their prices to change at a rate that is equal to the competitive rate of profits. However, these changes need not affect the prices of the other commodities, including the prices of the resources that are actually extracted. Hence, in Ricardo's argument the Hotelling Rule may be said to be effective, but its effects may be limited to changing prices of the conserved amounts of exhaustible resources only. The owners of deposits will obtain both royalties and rents, in the course of time rents will fall and royalties rise, and the sum of both may remain constant. If this condition is met, then these price changes will not affect any other prices in the economic system. Ricardo's argument may be said to implicitly correspond to this case.

\section{References}

Hotelling H. (1931). The economics of exhaustible resources, Journal of Political Economy, 39, pp. $137-75$.

Krautkraemer, J. A. (1998). Nonrenewable resource scarcity, Journal of Economic Literature, XXXVI, pp. 2065-2107.

Kemp, M. C. and Long, H.V. (1984) The role of natural resources in trade models, in R.W. Jones and P. B. Kenen (eds), Handbook of International Economics, volume 1 (International Trade), Amsterdam: Elsevier, pp. 367-417.

Kurz H. D., Salvadori N. (1995). Theory of Production. A Long-Period Analysis, Revised paperback edition 1997, Cambridge, U.K.: Cambridge University Press.

Kurz H. D., Salvadori N. (2000). Economic dynamics in a simple model with exhaustible resources and a given real wage rate, Structural Change and Economic Dynamics, 11, pp. 167-79.

Kurz, H. D., and Salvadori, N. (2009). Ricardo on exhaustible resources, and the Hotelling Rule, in Aiko Ikeo and Heinz D. Kurz, eds, The History of Economic Theory Festschrift in Honour of Takashi Negishi, London: Routledge

Negishi, T. (1992). Comment. Minisymposium on 'The History of Economics and the History of Science', History of Political Economy, 24:1, $227-9$. 
Negishi, T. (1994). The Collected Essays of Takashi Negishi, Volume II: The History of Economics, Aldershot: Edward Elgar.

Ricardo D. (1951): On the Principles of Political Economy and Taxation, first edn 1817, in The Works and Correspondence of David Ricardo, edited by Piero Sraffa with the collaboration of Maurice H. Dobb, Vol. I, Cambridge: Cambridge University Press.

Smith A. (1976): An Inquiry into the Nature and Causes of the Wealth of Nations, first ed. 1776, Vol. II of The Glasgow Edition of the Works and Correspondence of Adam Smith, edited by R. H. Campbell, A. S. Skinner, and W. B. Todd, Oxford: Oxford University Press. In the text quoted as WN, book number, chapter number, section number, paragraph number. 